\title{
SHOULDER PAIN IN LONG-TERM HAEMODIALYSIS PATIENTS
}

\author{
A CLINICAL STUDY OF 166 PATIENTS
}

\author{
TAIZO KONISHIIKE, HIROYUKI HASHIZUME, KEIICHIROU NISHIDA, \\ HAJIME INOUE, MITSURU NAGOSHI
}

From Okayama University, Japan

$\mathbf{W}^{\mathrm{s}}$ Te reviewed 166 adult patients on long-term haemodialysis, dividing them into three groups according to the presence and type of shoulder pain. The 24 patients in group $A$, with spontaneous pain related to a supine posture, had been under haemodialysis for significantly longer than the others, and had a much higher incidence of carpal tunnel syndrome.

Open or arthroscopic resection of the coracoacromial ligament in 21 shoulders relieved pain during haemodialysis and night pain, and histological examination showed amyloid deposits and inflammatory-cell infiltration in the subacromial bursa in almost all cases, and in the tenosynovium of the bicipital groove in some.

We conclude that one type of shoulder pain experienced by patients on long-term haemodialysis is caused by the subacromial impingement of amyloid deposits. This should be distinguished from other types of shoulder pain, because it can be relieved by resection of the coracoacromial ligament.

J Bone Joint Surg [Br] 1996;78-B:601-5.

Received 8 February 1995; Accepted after revision 22 January 1996

T. Konishiike, MD

H. Hashizume, MD

K. Nishida, MD

H. Inoue, MD

M. Nagoshi, MD

Department of Orthopaedic Surgery, Okayama University Medical School, 2-5-1 Shikata-cho, Okayama 700, Japan.

Correspondence should be sent to Dr T. Konishiike.

(C)1996 British Editorial Society of Bone and Joint Surgery 0301-620X/96/41211 \$2.00
In patients on long-term haemodialysis, amyloid deposits are known to cause various osteoarticular and soft-tissue complications including carpal tunnel syndrome (Warren and Otieno 1975), periarticular bone cysts (Fenves et al 1986; Konishiike et al 1994a), and destructive spondyloarthritis (Kuntz et al 1984). Shoulder pain is often observed in such patients and is thought to be associated with amyloidosis (Kachel et al 1983; Charra et al 1984; Kurer, Baillod and Madgwick 1991), but details of the symptoms have not been reported. The cause of this pain is not clear, but it tends to be worse at night and during dialysis in a supine position, and improves in a sitting or standing position (Imai et al 1986; Okutsu et al 1991). It has been suggested that the pain is due to shoulder impingement caused by subacromial bursitis (Okutsu et al 1991). We have studied the characteristics of this changeable pain which we term 'dialysis shoulder'.

\section{PATIENTS AND METHODS}

We interviewed all 166 patients under treatment by haemodialysis at Shigei Hospital. There were 94 men and 72 women who had been having dialysis for an average of nine years (0.3 to 22.7). Their average age was 58.4 years (35 to 78$)$.

We were able to classify the patients' complaints of shoulder pain into three groups.

Group A $(\mathrm{n}=24)$. This included patients in whom pain was worse at night, during dialysis, or during the day when the patient was lying down; it decreased when sitting or standing. This pain was spontaneous, anterolateral in site and was associated with local tenderness over the coracoacromial ligament and sometimes the bicipital groove. The range of movement was sometimes reduced, especially in abduction, and a painful arc was present. About one-third of these patients had considerable loss of movement as a result of chronic contracture of the shoulder.

Group $B(\mathrm{n}=35)$. These patients had pain that did not clearly change according to their position.

Group $C(\mathrm{n}=107)$. This group had no pain.

We studied the relationships between these three groups of patients and the prevalence of carpal tunnel syndrome, the serum levels of $\beta_{2}$-microglobulin $\left(\beta_{2}-\mathrm{MG}\right)$ and of terminal-C parathyroid hormone (PTH-C). 
1!.)

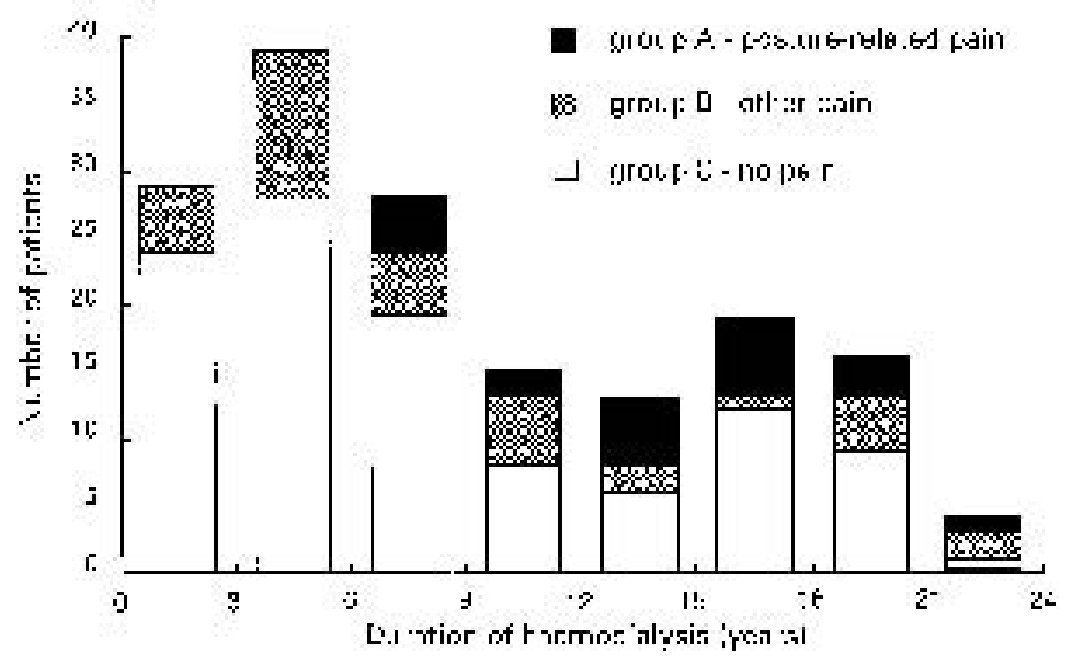

Fig. 1

Number of patients with shoulder pain (see text) related to the duration of haemodialysis.

We operated on 21 shoulders of 18 patients in group A who had intense shoulder pain. All had radiography and most had MRI. All these shoulders gave positive signs on the impingement injection test of Neer (1983). There were 11 women and 7 men. All the shoulders were treated by resection of the coracoacromial ligament, in 10 by open resection and in 13 by endoscopic resection. Two patients had open resection and then a later endoscopic resection. Both coracoacromial and transverse humeral ligaments were resected in 16 shoulders in which there was evidence of bicipital groove pain.

The tissues obtained from the subacromial bursa and the tenosynovium of the biceps groove were studied histologically, using haematoxylin and eosin staining with Congo red to demonstrate amyloid deposits.

The mean follow-up after operation was 9.5 months ( 3 to 21).

\section{RESULTS}

The duration of haemodialysis was related to the incidence of shoulder pain (Fig. 1). In group A 75\% (18/24) of patients had had over ten years of dialysis, in group B $37 \%$ (13/35), and in group C 31\% (33/107). The earliest appear- ance of group-A symptoms was at 6.5 years after the start of haemodialysis; at ten years, $48 \%$ of patients had some shoulder pain and $28 \%$ had posturally-related group-A complaints.

We found no significant difference between the three groups in average age or levels of $\beta_{2}-\mathrm{MG}$ or PTH-C, but patients with group-A pain had received dialysis for significantly longer than the mean for all patients (14.0 years, $\mathrm{p}<0.01)$. Group-A symptoms were closely associated with carpal tunnel syndrome $(66.7 \%, \mathrm{p}<0.01)$ (Table I).

All the 21 shoulders in the surgical group showed tenderness over the coracoacromial ligament, and 16 of them had tenderness over the bicipital groove $(76 \%)$.

The arthroscopic appearance (Universal Subcutaneous Endoscope System; Biomet Inc, Warsaw, Indiana) was that of subacromial bursitis with amyloid deposits impinging between the coracoacromial ligament and the rotator cuff. After release of the ligament, the impingement ceased and allowed smooth movement of the rotator cuff.

In all 21 shoulders, pain at night and during haemodialysis was relieved by the surgery. There was complete loss of pain in 15 shoulders, but six still had slight night pain. In two patients, shoulder pain recurred six months after open resection. Repeat arthroscopy in these showed a

Table I. The relationship between type of shoulder symptoms, age, duration of haemodialysis and other factors in 166 patients

\begin{tabular}{|c|c|c|c|c|}
\hline Shoulder pain* & $\begin{array}{l}\text { Mean } \\
\text { age } \\
(\mathbf{y r})\end{array}$ & $\begin{array}{l}\text { Mean duration } \\
\text { of haemodialysis } \\
\text { (yr) }\end{array}$ & $\begin{array}{c}\beta_{2} \text {-MG } \\
(\mu \mathrm{g} / \mathrm{dl})\end{array}$ & $\begin{array}{l}\text { Carpal tunnel } \\
\text { decompression } \\
\text { (percentage) }\end{array}$ \\
\hline Group A $(n=24)$ & 59.3 & 14.0 & 34.6 & 66.7 \\
\hline Group B $(\mathrm{n}=35)$ & 58.0 & $9.2 \neq$ & 36.6 & $31.0 \ddagger$ \\
\hline Group C $(n=107)$ & 59.0 & 7.9 & 34.7 & 7.5 \\
\hline
\end{tabular}

\footnotetext{
$*$ see text

$\dagger \mathrm{p}<0.05$

$\ddagger \mathrm{p}<0.01$
} 


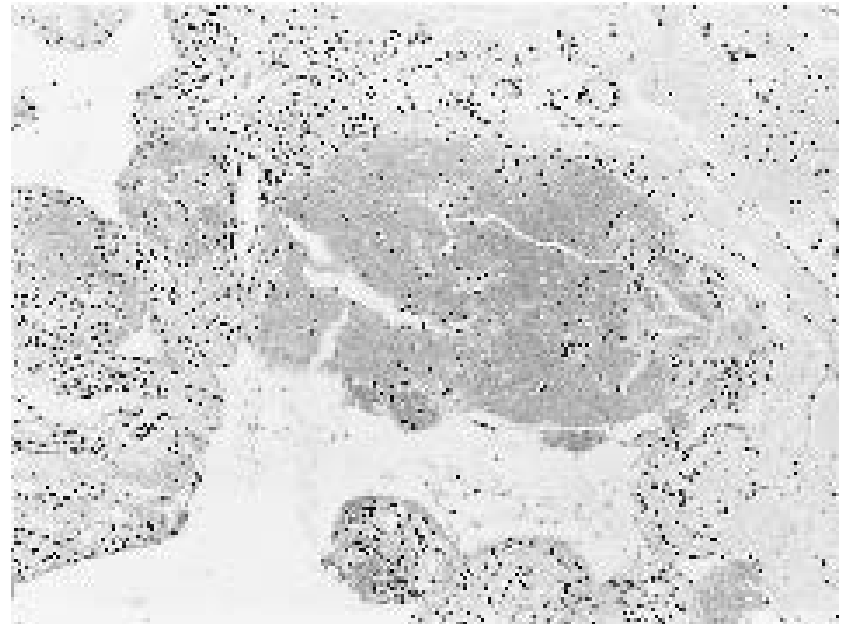

Fig. 2

Biopsy of subacromial bursa showing amyloid deposition and the proliferation of fibroblasts (haematoxylin and eosin, Congo red $\times 90$ ).

fibrous band over the subacromial bursa with inflammatory granulation tissue and amyloid deposits. In both cases, the shoulder pain disappeared after endoscopic resection of the fibrous band and subacromial bursa. There was no improvement in the range of movement.

The pathological findings in resected specimens included marked amyloid deposits in 19 of the 21 subacromial bursae and in 15 of the 16 biopsies of the tenosynovium of the biceps groove. There was proliferation of fibroblasts in all cases, but no gross fibrosis (Fig. 2).

Radiographs of the surgical group showed no acromial spurs or acromioclavicular osteophytes but 12 of the 21 shoulders had humeral-head erosions and two showed acro-

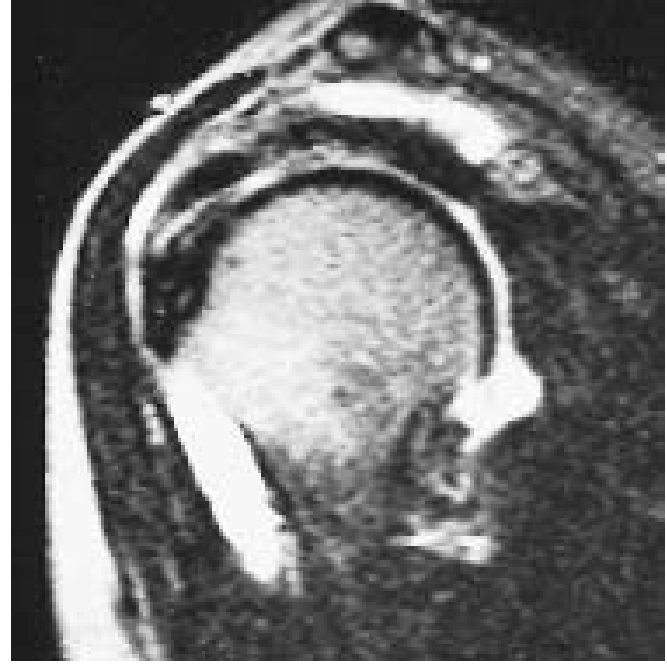

Fig. 3

T2-weighted MRI of the right shoulder of a 44-year-old man with group-A pain after 18 years of haemodialysis. There is subacromial bursitis and glenohumeral synovitis.

mioclavicular bone erosions. Of the 17 shoulders studied by MRI, 14 showed subacromial bursitis, 13 had glenohumeral synovitis (Fig. 3) and seven had massive deposits of inflammatory granulation tissue (Figs $4 a$ and $4 b$ ).

\section{DISCUSSION}

Shoulder pain is a common complaint in long-term haemodialysis patients. Imai et al (1986) found shoulder pain in $17.9 \%$ of patients who had had dialysis for over ten years. Kurer et al (1991) reported an incidence of $33.7 \%$, Sethi et al (1990) 47\%, and we have found 48\%. The high incidence of shoulder pain in dialysis patients with carpal tunnel

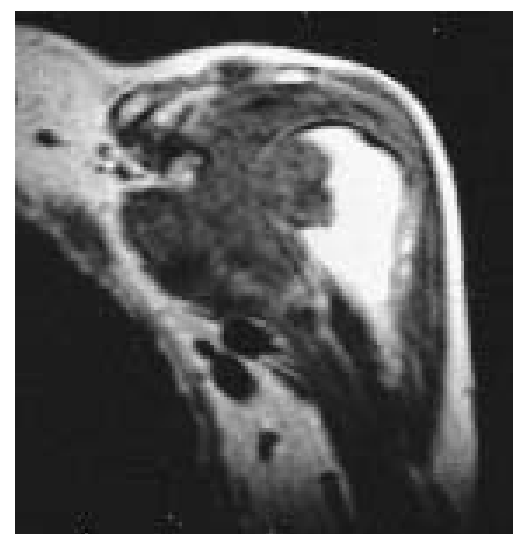

Fig. 4a

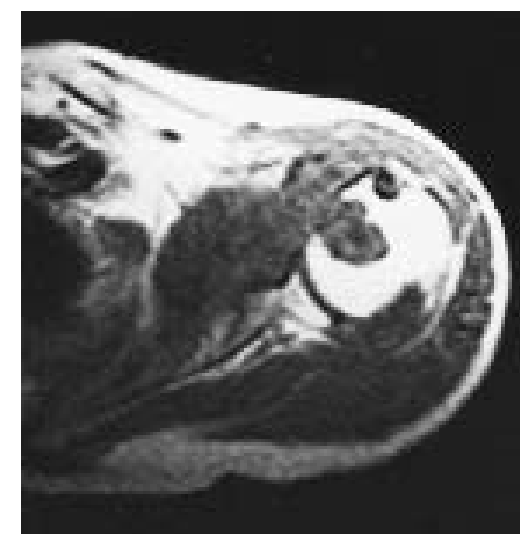

Fig. $4 \mathrm{~b}$

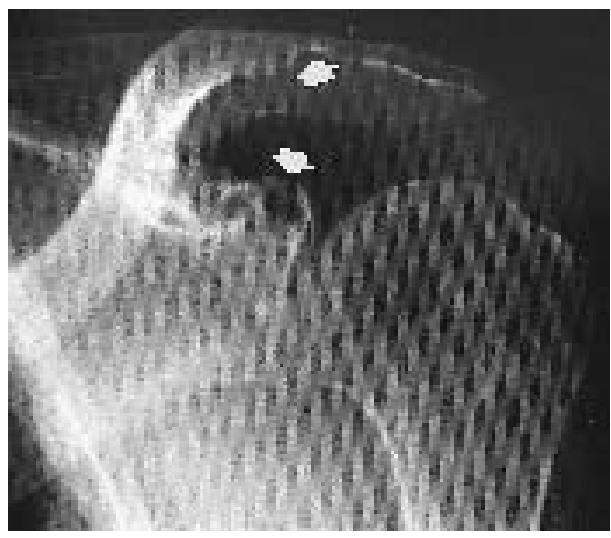

Fig. 4c

Figure 4a - T1-weighted MRI of the left shoulder of a 60-year-old woman with group-A pain after 20 years of haemodialysis. There is extensive inflammatory granulation tissue in the subacromial bursa and glenohumeral joint. The shoulder pain was relieved after resection of the coracoacromial ligament. Figure $4 \mathrm{~b}-$ The corresponding transverse T1-weighted MRI shows the bone cyst caused by inflammatory granulation tissue and tenosynovitis in the bicipital groove. Figure $4 \mathrm{c}-\mathrm{A}$ plain radiograph shows bony erosions around the joint capsule and ligament insertions (white arrows). 


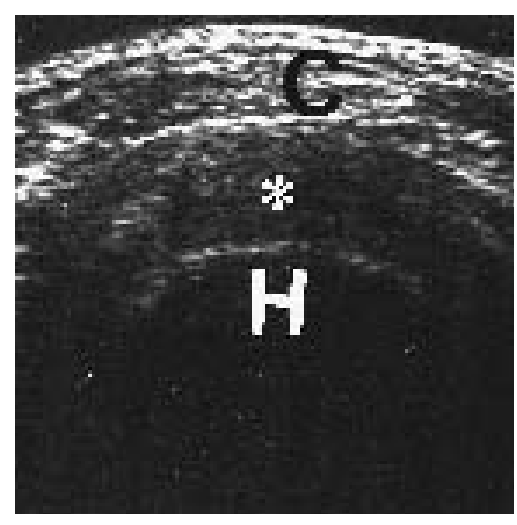

Fig. 5a

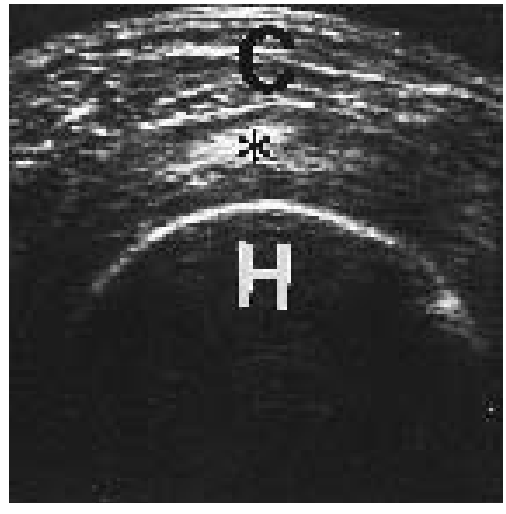

Fig. 5b
Ultrasonic images of the right shoulder of a 39 -year-old woman with group-A pain (haemodialysis duration 20 years) in the sitting position (a), and in the supine position (b). There is narrowing of the subacromial space and some irregularity of the coracoacromial ligament in the supine position, with reduction of the volume of the subacromial space. ( $\mathrm{H}$, humeral head; $\mathrm{C}$, coracoacromial ligament; *, subacromial space). syndrome also suggests that both may be due to amyloidosis (Kachel et al 1983; Charra et al 1984).

Okutsu et al (1991) were the first to describe the mechanism of the shoulder pain as impingement between the coracoacromial ligament and the diseased rotator cuff as seen arthroscopically. They obtained good results by resection of the coracoacromial ligament, which increases the volume and height of the subacromial space in a manner similar to decompression of the carpal tunnel.

We classified our haemodialysis patients according to the nature of their shoulder pain, and showed that group A was closely associated with carpal tunnel syndrome and duration of dialysis, and that $90 \%$ of the surgically-treated shoulders in this group had amyloid deposits in the subacromial bursa. We consider that the symptoms in group A were closely related to dialysis-associated amyloidosis; those in group B with no relation to posture could be due to other shoulder conditions.

All of our haemodialysis patients had high serum levels of $\beta_{2}-\mathrm{MG}$, but we found no significant correlation with our symptom groups. Ogawa, Saito and Ono (1989) also found no correlation between serum levels of $\beta_{2}-\mathrm{MG}$ and the presence of dialysis-associated amyloid osteoarthropathies. These findings indicate that factors other than chronic accumulation of $\beta_{2}-\mathrm{MG}$ are important. It seems possible that the recently discovered acid $\beta_{2}-\mathrm{MG}$ has a role, and may be a major pathogenic component in dialysis-related amyloidosis (Maeda and Miyata 1994).

We also found no relationship between group-A shoulder symptoms and serum levels of PTH-C. In general, dialysisrelated amyloidosis has been reported to have no such correlation (Ogawa et al 1989; Homma et al 1992; Konishiike et al 1994a) and this indicates that the shoulder pain is not caused by secondary hyperparathyroidism.

Arthroscopy allowed us to see the dynamic relationship between the coracoacromial ligament and the rotator cuff (Okutsu et al 1992), and confirm that impingement between them was relieved by resection of the ligament. Shoulder pain in long-term haemodialysis patients at night and in a supine position during treatment is secondary to subacro- mial bursitis; related tenderness in the biceps groove seems to result from stenosing tenosynovitis of the long tendon of biceps (Figs 4a and 4b). It is known that bursae as well as the synovium are target organs for amyloid deposition (Fernandez et al 1990; Reese, Hopkovitz and Lifschitz 1988; Konishiike et al 1994b), and it seems that the change in the relative position of the humeral head in an upright posture gives temporary relief from pain by expanding the volume of subacromial space (Figs 5a and 5b).

In some of our amyloidosis patients, there were bony erosions near the joint capsule and ligament insertions (Fig. 4c), due to invasion by inflammatory granulation tissue (Ogawa et al 1989; Konishiike et al 1994a,b), but we found no increase in acromial spurs or acromioclavicular osteophytes. This and the MRI and pathological findings confirm that the symptoms in our group-A patients were not caused by subacromial impingement due to degenerative change.

Shoulder pain in long-term haemodialysis patients which is related to a supine position should be called 'dialysis shoulder'. It is important to distinguish this from other types of shoulder pain, because treatment is easy, and good results can be expected from arthroscopic surgery (Okutsu et al 1991).

No benefits in any form have been received or will be received from a commercial party related directly or indirectly to the subject of this article.

\section{REFERENCES}

Charra B, Calemard E, Uzan M, et al. Carpal tunnel syndrome, shoulder pain and amyloid deposits in long-term haemodialysis patients. Proc Edta-Era 1984;21:291-5.

Fenves AZ, Emmett M, White MG, Greenway G, Michaels DB. Carpal tunnel syndrome with cystic bone lesions secondary to amyloidosis in chronic hemodialysis patients. Am J Kidney Dis 1986;7:130-4.

Fernandez E, Baro P, Montoliu J, Campistol JM, Sole M. Dialysisassociated amyloidosis presenting as a tumour in the elbow. Nephrol Dial Transplant 1990;5:237.

Homma N, Gejyo F, Kobayashi H, et al. Cystic radiolucencies of carpal bones, distal radius and ulna as a marker for dialysis-associated amyloid osteoarthropathy. Nephron 1992;62:6-12.

Imai K, Tamaki T, Inoue S, Hosaka E. Complication of hemodialysis patients in the upper extremities. JJpn Soc Surg Hand 1986;3:171-4.

Kachel HG, Altmeyer P, Baldamus CA, Koch KM. Deposition of an amyloid-like substance as a possible complication of regular dialysis treatment. Contrib Nephrol 1983;36:127-32. 
Konishiike T, Hashizume H, Nishida K, Inoue H, Nanba T. Cystic radiolucency of carpal bones in haemodialysis patients: an early indicator of the onset of carpal tunnel syndrome. J Hand Surg [Br] 1994a; $18: 630-5$.

Konishiike T, Hashizume H, Nishida K, Inoue H, Moriwaki K. Cubital tunnel syndrome in a patient in long-term haemodialysis. J Hand Surg [Br] 1994b;19:636-7.

Kuntz D, Naveau B, Bardin T, et al. Destructive spondylarthropathy in hemodialyzed patients: a new syndrome. Arthr Rheum 1984; 27:369-75.

Kurer MHJ, Baillod RA, Madgwick JCA. Musculoskeletal manifestations of amyloidosis: a review of 83 patients on haemodialysis for at least 10 years. J Bone Joint Surg [Br] 1991;73-B:271-6.

Maeda K, Miyata T. Relation between dialysis-related amyloidosis and advanced glycation end products (AEGs). J Jpn Soc Dial Ther 1994 $27: 1119-26$

Neer CS II. Impingement lesions. Clin Orthop 1983;173:70-7.
Ogawa H, Saito A, Ono M. Inflammation as the possible cause of cystic radiolucencies in carpal bones of patients on hemodialysis. ASAIO Trans 1989;35:317-9.

Okutsu I, Ninomiya S, Takatori Y, et al. Endoscopic management of shoulder pain in long-term haemodialysis patients. Nephrol Dial Transplant 1991;6:117-9.

Okutsu I, Ninomiya S, Takatori Y, Hamanaka I, Schonholtz GJ. Coracoacromial ligament release for shoulder impingement syndrome using the universal subcutaneous endoscope system. Arthroscopy 1992;8:2-9.

Reese W, Hopkovitz A, Lifschitz MD. B2-microglobulin and associated amyloidosis presenting as bilateral popliteal tumors. Am J Kidney Dis 1988;12:323-5.

Sethi D, Morgan TCN, Brown EA, et al. Dialysis arthropathy: a clinical, biochemical, radiological and histological study of 36 patients. $Q J$ Med 1990;282:1061-82.

Warren DJ, Otieno LS. Carpal tunnel syndrome in patients on intermittent hemodialysis. Post-grad Med J 1975;51:450-2. 